\title{
The Lebanese Kishk: A Traditional Dairy Product in a Changing Local Food System
}

\author{
Mabelle Chedid ${ }^{1}$, Salwa Tohmé Tawk ${ }^{2}$, Ali Chalak ${ }^{3}$, Sarah Karam ${ }^{1} \&$ Shadi K. Hamadeh ${ }^{1}$ \\ ${ }^{1}$ Environment and Sustainable Development Unit, Faculty of Agriculture and Food Sciences, American \\ University of Beirut, Lebanon \\ ${ }^{2}$ Faculty of Agriculture and Veterinary Sciences, Lebanese University, Lebanon \\ ${ }^{3}$ Department of Agriculture, Faculty of Agriculture and Food Sciences, American University of Beirut, Lebanon \\ Correspondence: Salwa Tohmé Tawk, Associate Professor, Faculty of Agriculture and Veterinary Sciences, \\ Lebanese University, BP 55-484, Dekwaneh, Beirut, Lebanon. E-mail: salwatawk@ gmail.com
}

\author{
Received: February 6, 2018 Accepted: February 22, 2018 Online Published: June 11, 2018 \\ doi:10.5539/jfr.v7n5p16 URL: https://doi.org/10.5539/jfr.v7n5p16
}

\begin{abstract}
This paper focuses on analyzing the production chain of traditional kishk prepared with wheat and milk in two Lebanese regions, the West Bekaa and the Chouf. It aims at assessing kishk processing to analyze the sustainability of this traditional product especially under the impact of changing wheat production and milk availability. A survey was conducted at the level of kishk producers and wheat farmers to identify the different production systems based on their scale and their practices. Results showed that kishk production has been sustained by rural women in the designated areas and was not affected by the changes that have occurred in the wheat sector which included introduction of new wheat varieties; on the contrary, this traditional product has adopted the new varieties. In addition, the versatility of kishk recipe prepared from cow, sheep or goat milk, makes this dairy product resilient to changes in milk availability and sources. However, the authors found that conserving traditional kishk requires substantial efforts in marketing, certification, and quality control.
\end{abstract}

Keywords: kishk, Lebanon, local food systems, milk, sustainable food, traditional food system, wheat

\section{Introduction}

Traditional food reflects culture, history and lifestyle; however, the world of globalization has been threatening culinary heritage and exposing many of the traditional food to extinction (Trichopoulou et al., 2006). Efforts to sustaining this heritage requires studies to understand the production process, the components and the impacts any change might impose on traditional food and its conservation.

Kishk, a traditional dairy product prepared with bulgur (dry cracked wheat) fermented in milk or yogurt, originates from two local products: wheat and milk (Ministry of Agriculture [MoA], 2007). These two components have differently responded, through time, to the various changes to which they were subject to, ranging from political changes on the national and regional levels including agricultural policies, fluctuations in the local and international markets and economy, to climate and social changes. While wheat production in Lebanon has changed in terms of cultivated land surfaces and used seed varieties (Ministry of Environment [MoE], United Nations of Development [UNDP] \& Global Environment Facility [GEF], 2016; Lebanese Agricultural Research Institute [LARI], 2014), goat and sheep milk production showed more resilience facing different stressors and was able to maintain its production, however with a shift from a traditional pastoral system to a more sedentary one (Hamadeh et al., 1999; Bistanji et al., 2000).

This wheat and milk based fermented product has been prepared and consumed in Lebanon since the $10^{\text {th }}$ century (Al Ghazi, 2001) mainly in the Bekaa region where wheat is grown then harvested starting June. It is prepared with cow, sheep or goat milk; however, while goat milk gives it a typical acidic (pungent) taste, cow milk is more used to prepare commercial kishk. Kishk is prepared during summer to serve as a provision for winter time. It is also known in other Arab countries like Syria, Jordan and Egypt with variations in its preparation method (Odunfa \& Adeyele, 1985). The low moisture content and acidic $\mathrm{pH}$ of the final product makes it safe against the growth of pathogenic micro-organisms (Hamad \& Fields, 1982). Although kishk is produced exclusively in rural areas, its consumption is common all over the country and constitutes an important part of the winter diet when 
consumed as a thick soup containing Qawarma (preserved lamb meat) and eaten with bread (Salibi, 1997) as well as in pizza or man'ousheh (flat dough with a kishk-based topping).

\subsection{Wheat Production in Lebanon}

The yearly consumption of wheat in Lebanon ranges between 400000 to 450000 tons (Harrigan, 2014), of which around one forth is locally produced. The general agricultural census prepared by the Ministry of Agriculture (MoA), the Food and Agriculture Organization (FAO) and the Italian Cooperation in 2012 reports that $70 \%$ of the cereals planted in Lebanon is wheat, covering a surface of 29840 ha of which $44 \%$ are in the Bekaa (central and West) and only 14\% in Baalbeck and Hermel (Northern Bekaa) (MoA \& FAO, 2012). Zero percent is reported in Mount Lebanon. The main planted varieties of wheat in Lebanon are soft $(23 \%)$ and hard or durum wheat (77\%), the latter being used for the local food industry of bulgur, kishk, freekeh (roasted green wheat) and pasta rather than for bread. Between 2012 and 2016, an average of 140000 tons of wheat were produced; most are processed by the local mills into flour and bran, and the rest are used as cracked whole wheat for local traditional recipes (FAO, 2018; Chalak \& Sabra, 2007). Although wheat planted surfaces were increasing over the years, wheat production has declined mainly due to variability of rain and fluctuation of temperatures (MoE, UNDP \& GEF, 2016).

\subsection{Small Ruminant Production in Lebanon}

Small ruminant production has always been an integral part of the rural communities in Lebanon, contributing to the livelihoods of these communities by securing mainly milk and meat products.

Pastoralism in Lebanon has witnessed several changes throughout the years (Hamadeh et al., 1999; Bistanji et al., 2000); it has endured many pressures such as 1) lack of policies related to pastoralism and land tenure, 2) increasing urbanization at the expense of pastures, 3) decreasing rural population along with a decline in the interest of the new generations to invest in the sector, 4) lack of technical skills for pasture management coupled with weak government support, 5) climate change with predicted rising temperatures and severe droughts, 6) political and security situation in the region, and 7) uncontrolled borders and market prices. Nonetheless, the system has proved to be resilient, as proven by the recorded numbers of augmenting herds and dairy production (FAO, 2011). Moreover, the national small ruminant herd, composed of the local black goat known as Baladi and the indigenous Awassi sheep both highly rustic, coupled with the adaptive strategies adopted by the shepherds including herd size modification, feed supplementation and income diversification (Dick et al., 2008) highly contributed to the survival of the pastoral system in the country. Furthermore, according to Roselier (2015), a growth of $76 \%$ in caprine dairy production accounting for over 54 million Euros has been recorded in Lebanon in 2014 accompanied with a rising consumer demand for goat dairy products such as labneh (strained yogurt), yogurt and different types of fresh and fermented cheeses including kishk.

Investigations have been previously undertaken to assess the nutritional composition, microbiological quality, and biophysical and rheological properties of the Lebanese kishk (Tamime et al., 1999a; Tamime et al., 1999b; Tamime \& O'connor, 1995; Tamime \& McNulty, 1999; Salameh et al., 2016). Such studies revealed the importance of the kishk product being highly nutritious characterized by its microbiological safety due to its overall inherent characteristics (Tamime \& O'connor, 1995; Tamime \& McNulty, 1999; Salameh et al., 2016). However, studies targeting the sustainability of this traditional product, especially under the impact of changing local food systems, are, to our knowledge, inexistant. Therefore, this study aims at filling this gap by analysing the production chain of kishk as influenced by the changes in wheat production and milk sources.

\section{Materials and Methods}

The methodology relies on the value chain analysis (Hellin \& Meijer, 2006; Tohmé et al, 2011; Tohmé et al, 2014) of kishk from the production of wheat and bulgur to making the kishk, while describing the sources of milk, the kishk recipe and the marketing channels.

Data was collected through a survey during summer of 2014 in the West Bekaa and Chouf regions known for their kishk production and consumption. Two different questionnaires based on open-ended and closed-ended questions related to the production practices and selected socio-economic aspects were developed each including about 30 questions: one for the wheat farmers and one for the kishk processors. During the interview the farmers were asked questions regarding their farming practices and origins of wheat landraces. In addition, processors of kishk were asked questions about processing practices and input sources. The questions related to the sustainability of wheat and kishk production were inspired from the sustainability indicators of the French model IDEA - Indicateur de Durabilité des Exploitations Agricoles - (Zahm et al., 2008).

In order to achieve a representative sample in the absence of any previously assessed statistical data, a 
geographical coverage was achieved to the largest extent in each region to avoid any selectivity bias. A total of 63 farmers and processors from the West Bekaa and 40 processors from the Chouf were interviewed. All producers were selected in a snowball sampling or chain sampling since they are sparsely distributed in the regions. Wheat producers representing small and large-scale farms and kishk producers were randomly selected with the help of local key informants in each region.

Descriptive statistics for the analysis of collected quantitative and qualitative data were conducted using STATA version 12 .

\section{Results}

\subsection{Kishk Production in West Bekaa and Chouf}

Kishk in the West Bekaa and Chouf is a traditional hand-craft product and a family activity carried at the household level and lead by the women; however, in some cases ( 2 in the West Bekaa and 4 in the Chouf), the husband was also involved in the production process. Although kishk is usually produced at the household level, five cases of production at a group level were identified within the studied sample (i) three groups of women in the West Bekaa, including two small dairy processing units and one agro-food cooperative, all of them selling directly to consumers; (ii) and two other groups of women working from their homes were identified in the Chouf and procuring kishk to a retail shop. The average production of kishk ranged between $5 \mathrm{~kg}$ to $500 \mathrm{~kg}$ per year per producer or group of producers. None of the producers was considered solely commercial as they all produced kishk for their household consumption in the first place.

\subsubsection{Mode of Production of Kishk}

Kishk making starts with soaking coarse bulgur in yogurt in a large clay bowl - replaced today with plastic ones - and rubbing the mixture daily for four days, until the bulgur totally absorbs the yogurt. During this time, yogurt is added every day to prevent the kishk from drying and salt is gradually added to protect it from mold growth. "Green" kishk is obtained after the mixture is left to ferment for nine days. "Green" kishk can either be consumed fresh like "labneh" (strained yogurt) or cheese, or conserved in glass jars with olive oil for ulterior use. The final steps of making dry kishk consist of spreading the green kishk on clean cloth sheets on the rooftop to dry under the summer sun while rubbing it every morning to break it into smaller pieces and make sure it dries well. When it totally dries, it is grounded in the mill into a fine powder and is consequently ready to be sold. According to the interviewed producers, rubbing of kishk used to be a social event gathering women from the neighborhood to help each other and share stories. This method of processing kishk is closer to the one described in Davidson by Zurayk and Abdul Rahman (2008), compared to other recipes documented by the same authors.

\subsubsection{Cost of Production and Labor Involved}

Kishk production is a labor-intensive process involving 3 to 5 persons during 20 days over a month approximately and sometimes longer depending on the produced quantity and whether the producers process wheat into bulgur or simply purchase bulgur. The average production per household is 50 kilograms.

Based on the information collected from women processors during the interviews, 2 kilograms of kishk processed at the household level costs on average between LBP (Note 1) 22950 (when yogurt and labneh are purchased ready-made) and LBP 17500 (when milk is purchased and yogurt and labneh are processed at the household level).

Therefore, the profit ranges between 37050 LBP and 42500 LBP per 2 kilograms of kishk or LBP 18525 and LBP 21250 per kilogram. The average kishk processor produces around 50 kilograms per season, thus generating profit between LBP 926500 and LBP 1253750 per season.

Hence, the cost of producing kishk depends on the origin of milk, yogurt and bulgur, and varies between LBP 8 745 and LBP 11475 per kilogram of kishk without accounting for labor. The average selling price of one kilogram of kishk is LBP 30 000, and the average quantity of kishk produced is 50 kilograms per season per household, thus generated revenue ranges between LBP 1062750 and LBP 926250 per season. Kishk production shows positive profitability for the different dairy ingredients used and irrespective of their source of procurement.

\subsubsection{Marketing and Packaging}

The marketing of kishk relies on direct sales to consumers through kinship and personal contacts upon pre-orders in the same town and/or neighboring towns and in the city. Few processors reported to regularly participate in weekly farmers' market in the capital. Kishk is sold in transparent plastic bags or cloth bags with no labelling indicating the used ingredients, the production date or the geographical location and nutritional information. 
Processors rely on the trust relationship with their clients and are reluctant to invest in extra packaging costs.

\subsection{Impacts of Wheat Production and Milk Sources on Kishk Production}

\subsubsection{Wheat Production}

Wheat remains a crop commonly planted in the Bekaa in rotation with vegetables and legumes on surfaces ranging between 0.2 and 300 ha, with an average yield of $4580 \mathrm{~kg} / \mathrm{ha}$, ranging between $1000 \mathrm{~kg} / \mathrm{ha}$ and 8000 $\mathrm{kg} / \mathrm{ha}$, and exceeding the average of $3000 \mathrm{~kg} / \mathrm{ha}$ reported in the latest national census (MOA \&FAO, 2012). In the Chouf area, wheat is no longer part of any farming system where traditionally it was a main crop planted on small terraces. The fragmentation of land holdings and the steep topography of terraces which are more adapted to fruit orchards, in addition to the unavailability of suitable harvesting equipment, were the main reason behind the decline of wheat production in the Chouf, and consequently its absence.

During the survey, farmers were asked about the wheat varieties they planted, their common names and source of procurement. Farmers referred to the local wheat grown in their region as "baladi", others used more specific names like "Bekaii" referring to the Bekaa or brown wheat (asmar), "Salamouneh" referring to its elongated form, and "Hawraneh" referring to the volcanic plateau Hawran in Syria; in addition, some called wheat by their color ahmar for brown and biyadi for white. These "baladi" or local varieties are used for processing the majority of the traditional by-products namely bulgur, kishk and flour for traditional "saj" flat bread. Both durum wheat (kasi) and soft wheat (tareh) are planted in the West Bekaa; however, to produce kishk and bulgur, only durum variety is used. Both brown and white wheat are used for processing; white bulgur is mainly used to process kishk to give it the light whitish color, as it is more preferred by consumers. Two sources of improved wheat varieties were identified: the Lebanese Agricultural Research Institute (LARI) which provided seeds to around $50 \%$ of farmers at subsidized prices, and commercial agricultural suppliers in the area who provided farmers with other varieties different than those supplied by LARI.

However, few farmers reported saving their own seeds from previous years for ulterior use, or even exchanging seeds with relatives and neighboring farmers. These farmers kept seeds for only two seasons before buying new ones. We were unable within the scope of this survey and the covered area to identify producers saving seeds from several years back. Moreover, none of the interviewed farmers referred to saving landrace seeds for their heritage value; they all denoted the high yields of the varieties available at LARI and the market.

While $68 \%$ of producers prefer to prepare kishk with white bulgur to give the final product a lighter color, the rest use the local wheat $(23 \%)$ and brown wheat $(9 \%)$ which gives kishk a darker color that is usually preferred by the producers' family for own consumption.

\subsubsection{Milk Sources}

Besides wheat, kishk production requires milk and yogurt. While almost all processors in the West Bekaa use goat milk to make kishk, the preference in the Chouf is more towards the use of cow milk or even a blend of goat and cow milk. In few reported cases, "labneh" (strained yogurt) is used instead of milk and yogurt, and the end-product considered of high quality is consumed by the processor's family and is not intended for sale.

Milk is either purchased from neighboring farmers or cooperatives or produced at home (Table 1). As for the yogurt (known as laban), if used in kishk making, it is either purchased from local farmers and dairies or processed from milk at home. In the West Bekaa, yogurt and milk are mainly purchased from neighboring producers or farmers. Only $18 \%$ of processors have their own milk production (from their own farm). The milk used is cow, goat milk or mixed cow and goat milk. Whereas in the Chouf area, $62 \%$ of the processors produce their own yogurt, $38 \%$ purchase the yogurt; $52 \%$ get their milk from their own livestock and $48 \%$ purchase it from neighboring farmers or cooperatives.

Table 1. Source of milk and yogurt used by kishk processors in the West Bekaa and Chouf

\begin{tabular}{lcccc}
\hline & \multicolumn{2}{c}{ Source of milk } & \multicolumn{2}{c}{ Source of yogurt } \\
\hline & Purchased milk & Milk from own farm & Purchased yogurt & Yogurt processed at home \\
\hline West Bekaa & $82 \%$ & $18 \%$ & $94 \%$ & $6 \%$ \\
Chouf & $48 \%$ & $52 \%$ & $38 \%$ & $62 \%$ \\
\hline
\end{tabular}

Yogurt and milk are not transported in refrigerated vehicles since processors consider that the distances separating them from the milk and yogurt producers are short (few minutes of travel).

The difference in the mode of procuring milk and yogurt between the West Bekaa and the Chouf shows a more farm-localized procurement system in the Chouf than in the West Bekaa as people in the Chouf tend to produce 
their raw material (milk or yogurt) rather than buying them. However, the procurement system adopted in the West Bekaa might be evidence of strong relationships between the different actors (processors and shepherds/farmers) involved in the kishk value-chain.

\section{Discussion}

\subsection{Kishk Production in West Bekaa and Chouf}

Sustaining traditional techniques and knowledge is essential in the preservation of the original identity of traditional food (Slow Food, 2013). This was demonstrated in the production of Stilton, a traditional cheese in the countries of Nottinghamshire, Leicestershire and Derbyshire when the use of pastoralized milk instead of raw milk deprived this traditional food from its aromatic richness and traditional identity. Hence, Slow Food is fighting for the reuse of raw milk in the production of Stilton cheese (Slow Food, 2017). So far, kishk has been preserved in its traditional way of production by the small-scale producers.

In addition, as this study reveals, kishk production is profitable, and kishk is highly demanded by the Lebanese population hence giving it an advantage for its preservation. However, marketing channels are not regulated, and packaging is poor lacking any kind of labelling (ingredients, the production date, the geographical location and nutritional information). If marketed appropriately, traditional products could have a significant competitive advantage based on their peculiarity as well as their nutritional and physiological advantages (Boros et al. 2013).

Therefore, building the capacities of kishk producers on food safety practices and improving their marketing skills would widen their opportunities not only in preserving a traditional food but also contributing to the livelihoods of the shepherds and producers involved in the value-chain. In addition, collective action has high potentials in addressing the inefficiencies, coordination problems and barriers to market access (Markellova et al., 2009); therefore, organizing agro-food cooperatives is highly recommended to aid kishk producers in overcoming challenges constraining access to markets and enticing the new generation to get involved in preserving the traditional food processing.

\subsection{Impacts of Changes in Wheat Production and Milk Sources on Kishk}

The results of this study revealing that kishk is being preferably produced with white bulgur, locally grown wheat and brown wheat agree with Zurayk and Abdul Rahman's (2008), according to whom coarse, soft and white bulgur is mostly used in kishk production. Processors have adapted their kishk production according to the wheat varieties available in the market. In addition, the fact that kishk recipe is already versatile and uses cow, sheep or goat milk, makes this dairy product more resilient to changes in milk availability and sources.

Among the challenges threatening the conservation of the original identity of traditional food is conserving its raw material. For example, before the intervention of Slow Food, tuma d'fé traditional cheese in the Langhe Cuneesi, Italy was at risk of dying out because its raw ingredient, milk product from Langhe breed sheep, was in danger of extinction (Taylor, 2012). Similarly, in the Peninsular Malaysia, Ikan masak tanah liat (clay-baked fish), opok-opok (glutinous rice crackers), pulut kukus dalam periuk kera (pitcher plant glutinous rice), and kebebe (mashed fruits in bamboo) are traditional dishes that are dying out due to the rarity of raw ingredients such as the ikan loma (a freshwater fish) which is close to extinction (Cheah, 2014). As revealed in this study, the kishk raw materials, wheat and dairy products, are highly available in Lebanon, and kishk identity so far is being preserved by using locally and freshly produced dairy products. Therefore, ensuring the sustainability of small-scale dairy production, and pertaining good connections between livestock breeders and kishk producers are essential to ensure the good quality and traditional characteristic of this product. However, concerning the other main raw ingredient, the wheat landraces traditionally used are being replaced by improved hybrid varieties of wheat which might be depriving the food from its original identity and added value. The reproduction of wheat landraces is a vital factor influencing the quality of food (Messa and Sottile 2015). Therefore, investigation and research are vital to identify the producers who are preserving and using wheat landraces in Lebanon at large; saving such varieties plays a major role in in-situ preservation of agro-biodiversity and cultural heritage.

\subsection{Conservation of Traditional Kishk}

Since kishk is highly demanded in urban settings, this fostered the probability for launching into the market commercially produced kishk hence misleading consumers and threatening rural production of this traditional food. This is a serious challenge confronting the conservation of traditional products (Trichopoulou et al., 2006), as supermarket dairy products can deteriorate a region's unique taste of place (Nuwer, 2014). In order to minimize the competitiveness of imitations and industrial production, the standardization and registration of the traditional products such as kishk would ensure their sustainability. 
Small food producers are the last guarantors ensuring the preservation of an endangered heritage; however, they are seldom capable of competing with multi-national producers. Therefore, certifying the traditional quality of their products is important to obtain the administrative and financial protection that is vital to their commercial sustainability (Billiard, 2017). In Asia, several national initiatives have been implemented towards using labels expressing certification marks or trademarks relevant to the legal regime. Such initiatives result in promoting local produce based on the concept of "One Village One Product" which originated in 1979 in Oita, Japan. This concept is based on a local product or industry characteristic of a certain region and turns it into a nationally and globally accepted one. It has been employed in several Asian countries such as the 'One Barangay, One Product' project in the Philippines, 'Satu Kampung, Satu Produk' initiative in Malaysia, the 'Back to Village' campaign in East Java, Indonesia, and the nationwide 'One Tambon, One Product' initiative in Thailand (Wong \& Fernandini, 2011; Zografos, 2007). In addition, Protected Designation of Origin and Protected Geographical Identification systems have been playing an important role in creating a strong regulatory framework across the European Union hence protecting traditional local products from falsification or imitation and promoting these products among consumers. However, even such systems must always be reconsidered to safeguard their efficiencies for small-scale producers. Small producers across EU for example have been facing difficulties in achieving market recognition and have been incapable of complying with the regulations due to their high costs (Slow Food, 2005).

Therefore, certifying the traditional quality of the kishk product would ensure its preservation and would support small-producers. In order to regulate the certification process and safeguard its practicality and effectiveness among small-scale producers, regional entities, from public and/or private sector can be important players in developing a system of quality control, certification, traceability, and labelling. In addition, incurring the production at group level / cooperative level would aid producers in complying with the standards and would facilitate the certification mechanism.

\section{Conclusion}

Kishk production has been sustained by rural women in the West Bekaa and Chouf and remains highly demanded in rural and urban settings. However, small-scale production of kishk lacks efficient marketing strategies and development of business plans; finding good marketing channels for this authentic product is a challenge and an opportunity at the same time to valorize this product.

Kishk recipe is proved to be flexible accommodating, cow, or goat milk; in addition, local farms are revealed to be maintained and local dairy products to be always available for purchase by kishk producers that do not own any farm. Hence, kishk production, till now, has not been affected by changes in the dairy sector. Similarly, kishk has not been affected by the changes occurring in wheat production as producers have adapted their kishk production according to the wheat varieties available in the market. Further studies are warranted to identify the origins of all wheat varieties specially the possibility of finding the landraces wheat varieties planted by the farmers across Lebanon and to deeply investigate the potential of protecting this traditional food by highlighting its unique identity and by assessing the added value of using landraces to up-grade the kishk and give it a traditional specialty value.

The authors presume that up-scaling and up-grading kishk production through certification, quality control, and labelling would play a substantial role in preserving this traditional food as well as supporting rural livelihoods in the regions where it is produced and creating a traditional food system that would encourage new generations to invest in.

\section{Acknowledgement}

The authors would like to thank the Lebanese National Council for Scientific Research (CNRS http://www.cnrs.edu.lb) for financially supporting this research.

\section{Reference}

Al Ghazi, N. (2001). Hadarat al-taam, Damascus: Dar El-Fikr (Arabic)

Bistanji, G., Hamadeh, S. K., Hajj, Hassan, S., Tami, F., \& Tannous, R. (2000). The potential of agroindustrial by-products in Lebanon as feed for livestock. Livest. Res. Rural Dev., 12(3), 6.

Billiard, E. (2017). Lost in tradition: an attempt to go beyond labels, taking Maltese food practices as a primary example, in Sebastia, B. (2016; 2017). Eating Traditional Food: Politics, identity and practices, Routledge Ltd, Florence.

Boros, P., Toth, Z. B., \& Fehér, O. (2013). The economic and marketing importance of local food products in the 
business policy of a Hungarian food retail chain. Procedia - Social and Behavioral Sciences, 81, 589-594. https://doi.org/10.1016/j.sbspro.2013.06.481

Chalak, L., \& Sabra, N. (2007). Lebanon: Second report on the state of plant genetic resources for food and agriculture. FAO. Retrieved from http://www.fao.org/pgrfa-gpa-archive/lbn/lebanon2.pdf

Cheah, C. (2014). Traditional dishes dying out. Retrieved from https://www.thestar.com.my/news/nation/2014/05/19/traditional-dishes-dying-out-scarcity-of-raw-ingredien ts-marks-end-of-old-flavours-and-cooking-style/

Dick, C. I., Ghanem, A. M., \& Hamadeh, S. K. (2008). Adaptation strategies of small ruminants production systems to environmental constraints in semi-arid areas of Lebanon, 8th European IFSA Symposium, Clermont-Ferrand (France)

FAO. (2011). FAOSTAT. Retrieved from http://faostat.fao.org/site/339/default.aspx

FAO. (2018). GIEWS-Global Information and Early Warning System, Country brief Lebanon. Retrieved from http://www.fao.org/giews/countrybrief/country.jsp?code=LBN

Hamad, M. A., \& Fields, M. L. (1982). Preliminary evaluations of a new type of kishk made from whey. Journal of Food Science, 47, 1140-1143. https://doi.org/10.1111/j.1365-2621.1982.tb07635.x

Hamadeh, S. K., Zurayk, R., El-Awar, F., Talhouk, S., Abi Ghanem, D., \& Abi-Said, M. (1999). Farming system analysis of drylands agriculture in Lebanon: An analysis of sustainability. Journal of Sustainable Agriculture, 15(2-3), 33-43. https://doi.org/10.1300/J064v15n02_05

Harrigan, J. (2014). An economic analysis of national food sovereignty policies in the Middle East: The case of Lebanon and Jordan. In Eds. Babar, Z. \& Mirgani, S. Food security in the Middle East. Oxford University Press.

Hellin, J., \& Meijer, M. (2006). Guidelines for value chain analysis. Food and Agriculture Organization.

LARI (Lebanese Agriculture Research Institute), MoA (Ministry of Agriculture in Lebanon). (2014). Wheat cultivation in Lebanon. In Arabic. 1-37.

Markelova, H., Meinzen-Dick, R., Hellin, J., \& Dohrn, S. (2009). Collective action for smallholder market access. Food Policy, 34(1), 1-7. https://doi.org/10.1016/j.foodpol.2008.10.001

Messa, M., \& Sottile, F. (2015). Slow Food's position paper on seeds. Retrieved from https://www.slowfood.com/sloweurope/wp-content/uploads/ING_position_paper_semi-1.pdf

MoA (Ministry of Agriculture). (2007). Project of agriculture census 2005. Ministry of Agriculture.

MoA (Ministry of Agriculture) \& FAO (Food and Agriculture Organization). (2012). Résultats globaux du module de base du recensement de l'agriculture 2010, 1-199.

MoE (Ministry of Environment), UNDP (United Nations Development Programme) \& GEF (Global Environment Facility). (2016). Lebanon's third national communication to the UNFCCC. Beirut, Lebanon.

Nuwer, R. (2014). BBC: The World's Most Endangered Food. Retrieved from http://www.bbc.com/future/story/20140401-the-worlds-most-endangered-food.

Odunfa, S. A., \& Adeyele S. (1985). Microbial changes during the traditional production of ogi baba, a West African fermented sorghum gruel. Journal of Cereal Science, 3, 173-180. https://doi.org/10.1016/S0733-5210(85)80027-8

Roselier M. (2015). Le Liban redécouvre le fromage de chèvre. Le commerce du Levant - L'Orient le Jour, published on August 21, 2015. Retrieved from https://www.lorientlejour.com/article/940150/le-liban-redecouvre-le-fromage-de-chevre.html

Salibi, K. S. (1997). Bhamdoun: Historical portrait of a Lebanese mountain village. Centre for Lebanese Studies.

Slow Food. (2005). PDO Blues. Retrieved from https://www.slowfood.com/pdo-blues/

Slow Food. (2013). Slow Food's contribution to the debate on the sustainability of the food system. Slow Food.

Slow Food. (2017). The international network Slow Cheese is born and supports producers of raw milk cheese from all over the world. Retrieved from https://www.slowfood.com/network/fr/reseau-international-slow-cheese-ne-soutient-producteurs-de-fromag e-lait-cru-monde-entier/

Tohmé Tawk, S., Moussa, Z., Hamadeh, S., \& Abi Saiid, D. (2011). Developing value chains in Amman, Jordan. 
Urban Agriculture Magazine, 25, 54-56.

Tohmé, S. T., Abi Saiid, M., \& Hamadeh, S. (2014). Urban agriculture and food security in the Middle Eastern context: A case study from Lebanon and Jordan. In Eds. Babar, Z., \& Mirgani, S. Food security in the Middle East. Hurst (UK) and Oxford University Press (US), 161-186

Taylor, M. L. (2012). Slow Food: what is its legacy? Retrieved from http://www.bbc.co.uk/food/0/19993496.

Trichopoulou, A., Vasilopoulou, E., Georga, K., Soukara, S., \& Dilis, V. (2006). Traditional foods: Why and how to sustain them. Trends in Food Science \& Technology, 17(9), 498-504. https://doi.org/10.1016/j.tifs.2006.03.005

Wong, T., \& Fernandini, C. (2011). Traditional cultural expressions: Preservation and innovation. Intellectual Property and Human Development: Current Trends and Future Scenarios, 175-217.

Zahm, F., Viaux, P., Vilain, L., Girardin, P., \& Mouchet, C. (2008). Assessing farm sustainability with the IDEA method-from the concept of agriculture sustainability to case studies on farms. Sustainable development, 16(4), 271-281. https://doi.org/10.1002/sd.380

Zografos, D. (2007). Legal Protection of Traditional Cultural Expressions in East and Southeast Asia: An Unexplored Territory?. Australian Intellectual Property Journal, 18(3), 167-178.

Zurayk, R., \& Abdul, Rahman, S. (2008). From Akkar to Amel, Lebanon's Slow Food Trail. Slow Food Foundation for Biodiversity and Slow Food Beirut. 150. ISBN 7000414-17-13.

\section{Notes}

Note 1. LBP, the Lebanese Pound, is the currency for Lebanon. Each USD 1 is equivalent to LBP 1500.

\section{Copyrights}

Copyright for this article is retained by the author(s), with first publication rights granted to the journal.

This is an open-access article distributed under the terms and conditions of the Creative Commons Attribution license (http://creativecommons.org/licenses/by/4.0/). 